\title{
PreVisão de COEFICIENTES de WiEbe PARA UM MOTOR SI BASEADO EM VARIÁVEIS DE CONTROLE
}

\author{
Thomaz Ernesto de Sousa Savio ${ }^{1.2}$, Luis Henrique Ferrari ${ }^{1.2}$ e Ezio Castejon Garcia ${ }^{1}$ \\ ${ }^{1}$ Instituto Tecnológico de Aeronáutica - ITA \\ ${ }^{2}$ Ford Motor Company - Brasil \\ E-mails: tsavio@ford.com, $\underline{\text { lferra21@ ford.com, ezio@ita.br }}$
}

\section{RESUMO}

A proposta deste trabalho é prever os coeficientes de Wiebe para um motor de ignição por centelha de quatro cursos $1.61 \mathrm{com}$ duplo comando de válvulas variável baseado em seis parâmetros de controle, trabalhando com E100. Os parâmetros de controle são: Rotação do motor, ponto de centelha, relação de equivalência (lambda), carga do motor (representada pela eficiência volumétrica absoluta), ponto de abertura de válvula de admissão e ponto de abertura de válvula de exaustão. A partir de dados experimentais são obtidas regressões lineares para as frações queimadas ao longo do angulo de manivela, e utilizando o método de mínimos quadrados, é possível encontrar uma combinação de duração de combustão, constante de Wiebe e expoente de Wiebe, garantindo mais fidelidade ao modelamento do fenômeno.

\section{INTRODUÇÃO}

Na realização de estudos envolvendo simulação de motores de combustão interna a pistão, geralmente aplicados em automóveis e caminhões, um dos limitantes é a confiabilidade quanto ao modelo de predição de liberação finita de calor. Para o caso de simulações de motores de carga homogênea e ignição por centelha, os softwares mais comuns utilizam uma curva de Wiebe para a modelagem e o usuário tem a opção de controlar os coeficientes da equação que rege tal curva, economizando tempo de processamento e ampliando a fidelidade do modelo, porém nem sempre estes coeficientes são conhecidos. Baseado em dados experimentais de um motor foi construído um software que, usando regressões lineares e interpolações, fornece ao engenheiro de motores os coeficientes necessários para calibrar uma curva de Wiebe de acordo com a condição de operação do motor.

\section{CURVA DE WIEBE}

A curva de Wiebe pode ser descrita por:

$$
f=1-e^{\left[-a \cdot\left(\frac{\theta}{\Delta \theta}\right)^{b}\right]}
$$


Onde $(f)$ é a fração queimada de combustível, $(\theta)$ é o ângulo em graus de virabrequim a partir da centelha, $(\Delta \theta)$ é a duração da combustão, $(a)$ é a constante de Wiebe e $(b)$ o expoente de Wiebe.

A energia liberada em forma de calor durante a combustão é diretamente proporcional a fração de combustível queimada, quando esta é conhecida a evolução de pressão e temperatura dentro da câmara de combustão pode ser obtida com maior precisão, resultando em simulações com maior nível de confiabilidade.

\section{PARÂMETROS DE CONTROLE}

Analisando o funcionamento do motor, podemos definir como parâmetros de controle: Rotação, ponto de centelha, relação de equivalência, carga e pontos de abertura das válvulas de admissão e exaustão.

A rotação do motor rege os níveis de velocidade do escoamento de ar e combustível dentro da câmara de combustão, o que influi na troca de calor com as paredes, no grau de turbulência do gás e na misturação dos reagentes, desta forma a rotação é um parâmetro importante na análise da combustão.

O ponto de centelha define o início da combustão, influenciando assim no regime de pressões ao longo do decorrer do movimento do pistão, impactando assim no desenrolar da combustão.

A relação de equivalência $(\lambda)$ define o grau de dissociação da reação de combustão, de modo que mais reações de dissociação tornam a combustão mais lenta, modificando assim os coeficientes da curva de Wiebe.

A carga, aqui representada pela eficiência volumétrica global, indica a massa de ar e, se combinada com a relação de equivalência, a massa de combustível admitida pelo motor, sendo que a massa de ar define a pressão obtida durante a compressão, influenciando então na evolução da combustão.

O ponto de abertura de válvula de admissão está diretamente ligado ao ponto de fechamento da válvula, dado que o sistema de comando de válvulas variável consegue apenas alterar o início e não a duração da abertura, e o ponto de fechamento da válvula de admissão definem o início da compressão e, indiretamente, o fator de compressão real do motor, logo, é influente no comportamento da combustão.

O ponto de abertura de válvula de exaustão, também ligado ao ponto de fechamento da válvula, apesar de ocorrer após a combustão influencia nesta porque altera a fração residual de gases queimados. Em motores que utilizam turbocompressor o efeito do ponto de válvula de exaustão é mais influente porque determina o "blow down", sendo este o responsável por fornecer energia a turbina, de modo que este efeito acaba por modificar a massa e pressão de ar admitido.

A combinação destes seis parâmetros de controle define um regime de operação do motor. 


\section{TRATAMENTO DE DADOS}

Os angulos de frações queimadas de 5\%, 10\%, 50\% e 90\% foram medidos para regimes de operação de 1000 RPM a 6500 RPM, de IDLE a WOT, os outros parâmetros de controle foram ajustados conforme a calibração do motor, resultando em um banco de dados com cerca de 300 regimes ensaiados para E100.

Usando o software Minitab ${ }^{\circledR}$, para cada rotação analisada foram obtidas regressões lineares baseadas nos outros cinco parâmetros de controle para predizer o ângulo de cada fração queimada analisada, resultando em quatro regressões lineares de entradas para cada rotação, sendo ao todo cinquenta e seis equações, todas com mais de $90 \%$ de representatividade.

Fazendo uma rotina em Matlab ${ }^{\circledR}$ foi possível concatenar todas as equações e então alimentálas com as com os parâmetros de controle de cada regime de operação, de modo a confrontar os resultados obtidos pelas regressões lineares e os resultados obtidos experimentalmente.

Para testar a validade dos resultados foi usado o software Minitab ${ }^{\circledR}$, que levou a conclusão que a população obtida pelas regressões lineares era igual à população de resultados obtidos experimentalmente, portanto as regressões lineares são válidas para a predição dos angulos de manivela das frações queimadas.

Na Figura 1, a análise estatística da população de regimes operacionais a $2000 \mathrm{rpm}$ mostram que a média e o desvio padrão da amostra são similares, denotando assim uma confiabilidade elevada dos dados. Já na figura 2, é mostrada a distribuição dos dados, nota-se que a média para cada conjunto de dados é a mesma e o comportamento destes dados são muito similares. Este mesmo caso ocorre em todas as outras rotações.

Figura 1 - Análise do ângulo de fração queimada para os regimes de operação a 2000 rpm, utilizando o software Minitab ${ }^{\circledR}$.

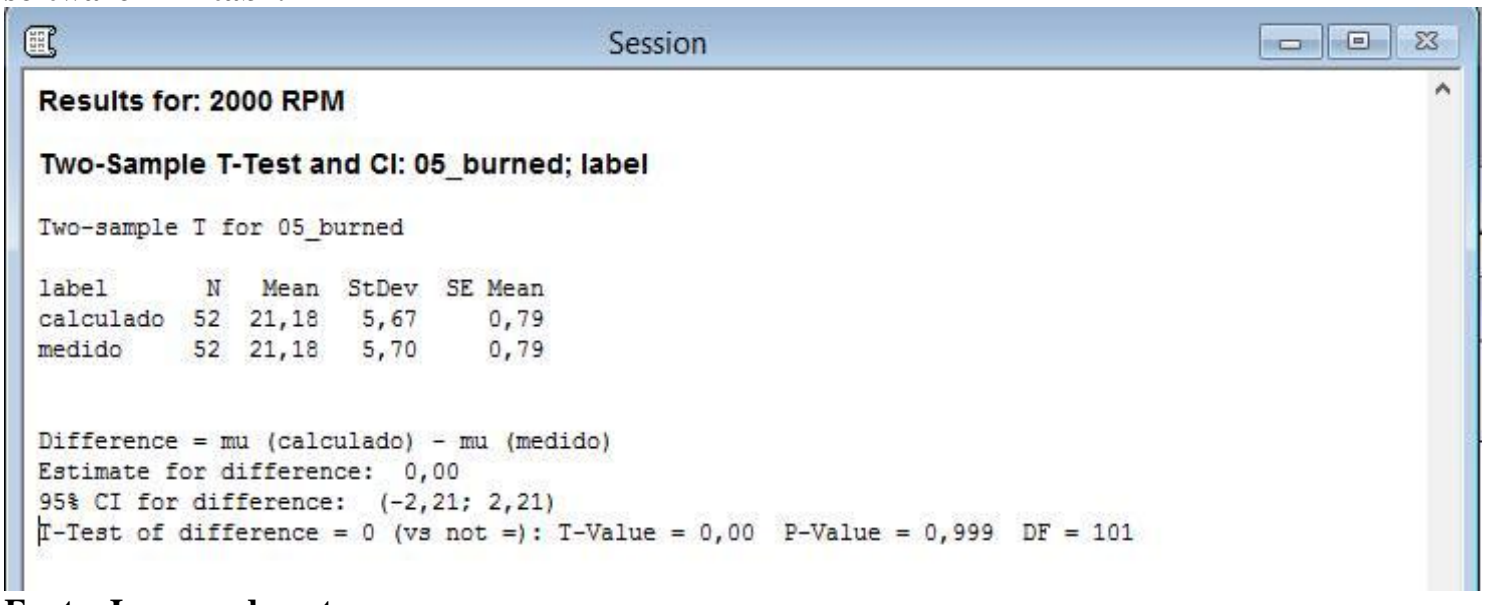

Fonte: Imagem do autor. 
Figura 2 - Dispersão dos ângulo de 5\% de fração queimada para os regimes operacionais de $2000 \mathrm{rpm}$.

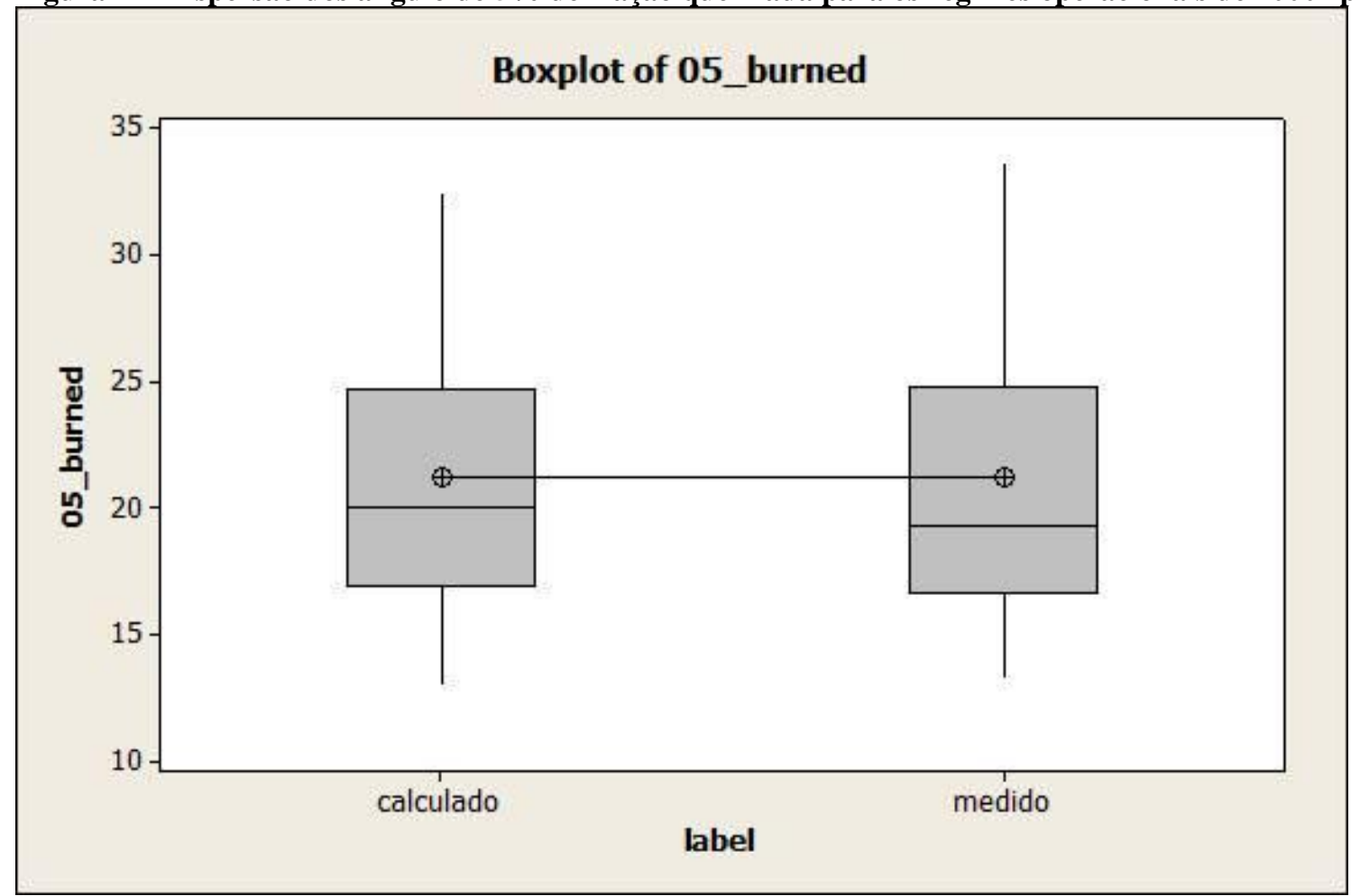

Fonte: Imagem do autor.

\section{OBTENÇÃO DOS COEFICIENTES DE WIEBE}

As curvas de Wiebe são projetadas a partir da minimização da função de erro entre a equação (1) e os pontos experimentais da fração queimada, esta minimização é obtida através de um algoritmo de otimização Nelder-Meat (ou método de descida simples), o qual é um algoritmo estruturado para problemas numéricos onde as derivadas da função não podem ser conhecidas, como no caso dos pontos de dados experimentais obtidos para a obtenção das curvas Wiebe.

Depois de definir o processo de minimização da função erro entre os pontos de medição e a curva projetada de Wiebe, os coeficientes de Wiebe (a, b) são definidos para cada rotação.

\section{CONCLUSÃO}

Neste trabalho, os coeficientes de Wiebe foram previstos baseados em seis parâmetros de controle para o E100. As regressões lineares de primeira ordem se mostraram capazes de predizer os ângulos de fração queimada com elevada confiabilidade.

O método de otimização se mostrou eficiente para predizer as três incógnitas para a projeção da curva de Wiebe, na figura 3 pode-se observar os quatro pontos mostrando o ângulo das respectivas frações queimadas e a curva de Wiebe obtida através do método de otimização que retornou as variáveis $a, b$ e $\Delta \theta$. 
Figura 3 - Curva de Wiebe projetada, ângulos de fração queimada e obtenção dos coeficientes de Wiebe.

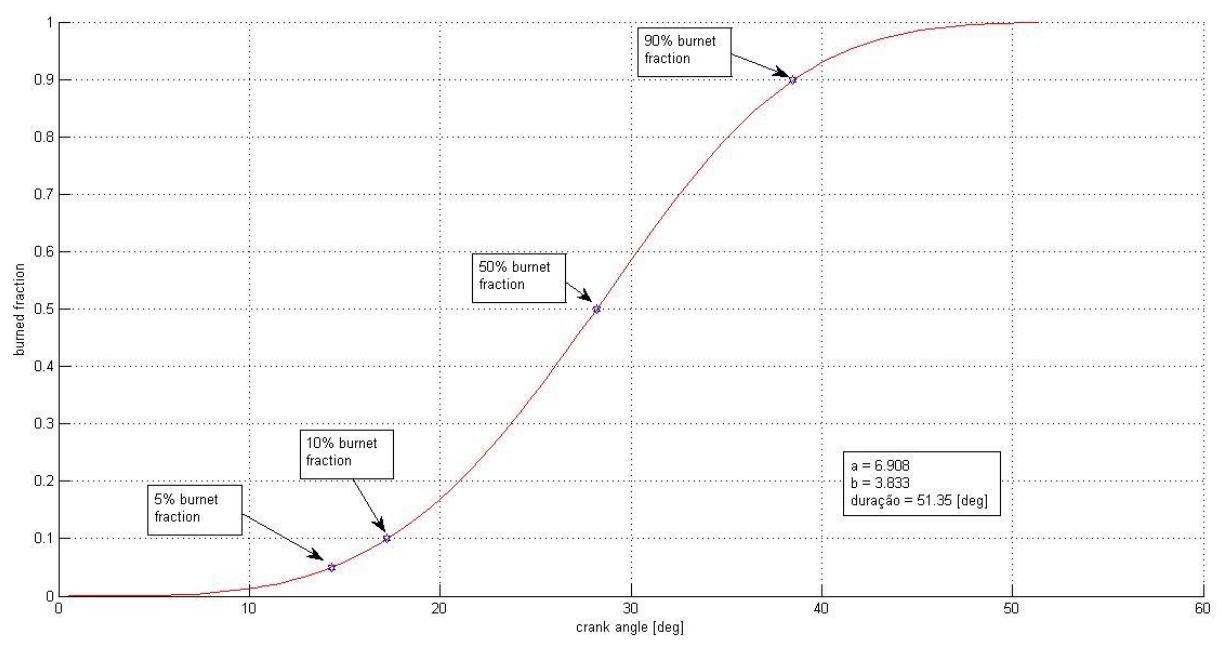

Fonte - Imagem do próprio autor.

\section{REFERÊNCIAS}

[1] KULESHOV, Andrey; Diesel RK website. Disponível em http://www.dieselrk.bmstu.ru/Eng/ Acesso em: 12/05/2014.

[2] HEYWOOD, John; Internal Combustion Engine Fundamentals, Massachusetts, EUA, 1988.

[3] NELDER, John A.; R. Mead (1965). "A simplex method for function minimization". Computer Journal 7: 308-313. 